Consultative Committee on Mass and Related Quantities (CCM)

Working Group on Gravimetry (WGG)

\title{
Regional Comparison of Absolute Gravimeters SIM.M.G-K1 Key Comparison
}

Table Mountain Geophysical Observatory (TMGO)

Boulder, Colorado

Pilot laboratory: NIST-Gaithersburg

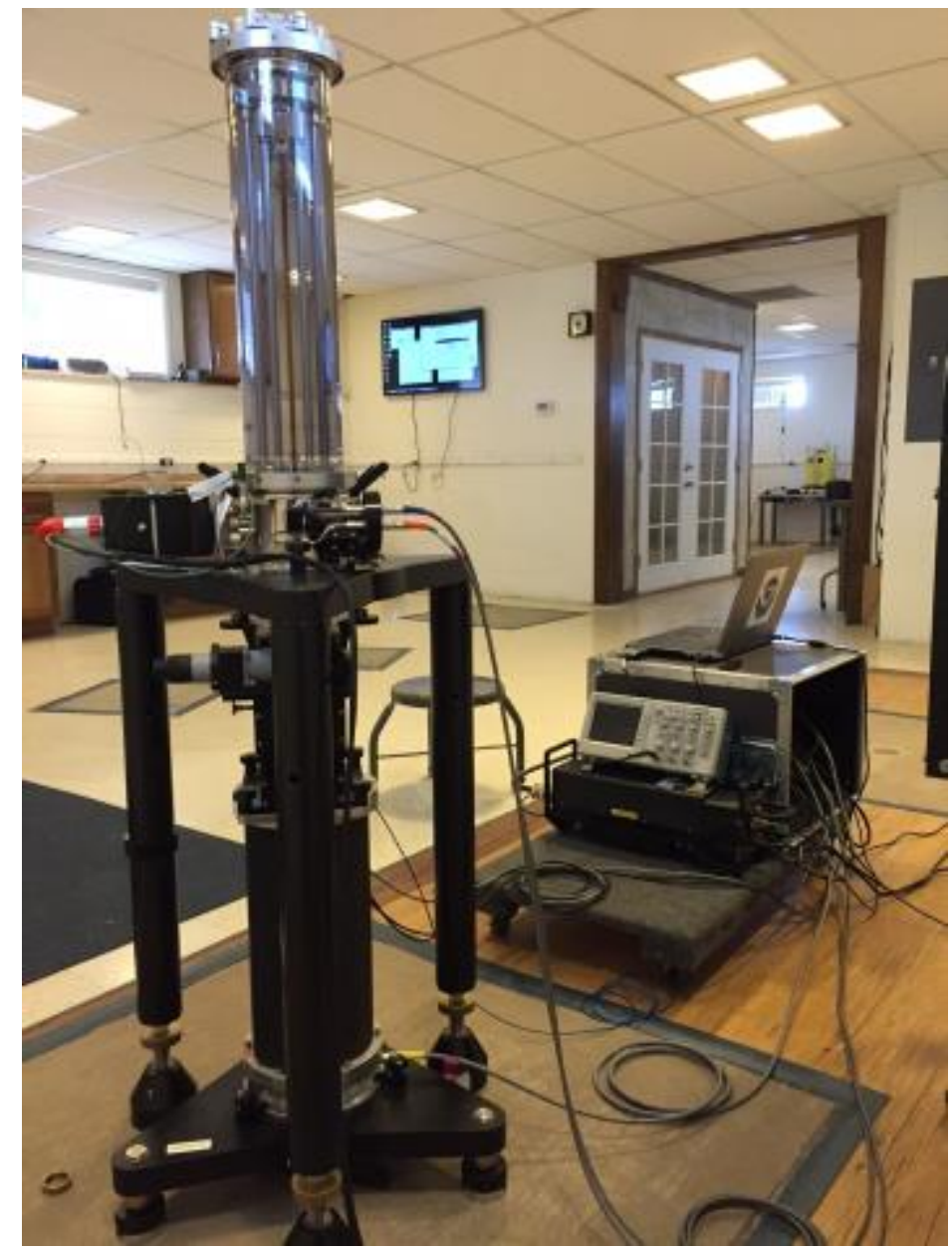




\section{Introduction}

The Regional Key Comparison of Absolute Gravimeters, SIM.M.G-K1, and a Pilot Study took place at the Table Mountain Geophysical Observatory (TMGO) near Boulder, Colorado between October 4 and October 16, 2016.

The procedures and schedule for the measurements were spelled out in the Technical Protocol, approved by all participants and the CCM-WGG. However, due to logistical constraints, a few teams were not able to attend, and the schedule was optimized accordingly.

Dr. David Newell of NIST, Gaithersburg, Maryland served as the Pilot Laboratory representative, while Dr. Derek van Westrum of NOAA-NGS, Boulder, Colorado served as the site host and coordinator. The comparison, SIM.M.G-K1, was organized in accordance with CIPM MRA-D-05 of the Consultative Committee on Mass and Related Quantities (CCM), and linked to the CCM.G-K2 [1] through EURAMET.M.G-K2 [2] via FG5X-216.

The list of participants and a description of the site (including vertical gravity gradients, observed tidal parameters, and superconducting gravimeter signal observed during the comparison) are presented, followed by a discussion of the analysis. The results of the data analysis, the degrees of equivalence (DoE) of the gravimeters, and the key comparison reference values (KCRVs) are also presented. For the final and official solution of the KCRVs, the contributions of absolute gravity data inconsistent at the $95 \%$ confidence level are investigated. Overall, the results and uncertainties indicate an excellent agreement among the gravimeters, with a standard deviation of the gravimeters' DoEs better than $1.3 \mu \mathrm{Gal}$.

The Pilot Study is a complete solution where all participating gravimeters were treated as equivalent in terms of their contribution to the definition of the reference values (RVs). The results of the Pilot Study are given in Appendix A.

Table 1. Participants in the comparison.

\begin{tabular}{|c|l|l|l|c|l|}
\hline$\#$ & Country & Institution & Gravimeter & $\begin{array}{l}\text { NMI or } \\
\text { DI }\end{array}$ & Operator(s) \\
\hline 1 & USA & NIST-Gaithersburg & FG5-204 & YES & David Newell \\
\hline 2 & USA & NOAA-NGS & FG5X-102 & NO & $\begin{array}{l}\text { Derek van Westrum } \\
\text { Jeff Kanney }\end{array}$ \\
\hline 3 & Canada & $\begin{array}{l}\text { National Research Council, } \\
\text { Canada }\end{array}$ & FG5-105 & YES & Jacques Liard \\
\hline 4 & Luxembourg & University of Luxembourg & FG5X-216 & YES & Olivier Francis \\
\hline 5 & USA & Micro-g LaCoste & FG5X-302 & NO & $\begin{array}{l}\text { Brice Lucero } \\
\text { Brian Ellis }\end{array}$ \\
\hline 6 & Italy & INGV & FG5-238 & NO & $\begin{array}{l}\text { Filippo Greco } \\
\text { Antonio Pistorio }\end{array}$ \\
\hline 7 & Netherlands & TU Delft & FG5-234 & NO & Rene Reudink \\
\hline 8 & Mexico & $\begin{array}{l}\text { CENAM \& National University } \\
\text { of Mexico }\end{array}$ & FG5X-252 & YES & $\begin{array}{l}\text { Alfredo Esparza } \\
\text { Ramirez }\end{array}$ \\
\hline 9 & Italy & Agenzia Spaziale Italiana & FG5-218 & NO & $\begin{array}{l}\text { Domenico Iacovone } \\
\text { Francesco Baccaro }\end{array}$ \\
\hline 10 & Canada & Natural Resources Canada & FG5-236 & NO & Jason Silliker \\
\hline 11 & USA & $\begin{array}{l}\text { National Geospatial Intelligence } \\
\text { Agency }\end{array}$ & FG5-107 & NO & Robert D Wheeler \\
\hline 12 & Germany & $\begin{array}{l}\text { Federal Agency for } \\
\text { Cartography and Geodesy }\end{array}$ & FG5-301 & NO & $\begin{array}{l}\text { Reinhard Falk } \\
\text { Axel Ruelke }\end{array}$ \\
\hline
\end{tabular}




\section{List of participants}

Table 1 lists the participants in the comparison. All gravimeters were of the FG5(X) type with two bulk interferometer systems (FG5-107 and FG5-301). Four institutions were a National Metrology Institute (NMI) or a Designated Institute (DI). These are shaded in pink.

\section{Site description and relative gravity measurements}

A schematic of the TMGO facility, renovated in 2010, is shown in Figure 1. Six of the 10 available piers (AK is permanently reserved for the SG) were employed during SGIM.M.G-K1: $\mathrm{AG}, \mathrm{AH}, \mathrm{AJ}, \mathrm{AQ}, \mathrm{AS}$, and AT. Each pier is constructed of approximately $1 \mathrm{~m}^{3}$ of concrete, isolated from the building's foundation. The building itself is located on top of a remote mesa, far from any cultural noise sources.

In the summer of 2014, LaCoste \& Romberg gMeters D43 and G6 were used to measure relative gravity values on a fixed tripod at three heights above each pier at TMGO. Three heights allow the determination of any nonlinearity in the gradient. A given measurement consists of six or more "laps" of each gravimeter up the three-tiered tripod. Each tier occupation consists of approximately twenty 10 second gravity samples. After first rejecting any sample outliers $(>3 \sigma$, $\mathrm{k}=1$ ), the instrument drift and any significant tares are removed. A weighted least-squares analysis provides a quadratic fit to all measured gravity differences (both instruments) simultaneously, resulting in the following function of gravity with height:

$$
g(z)=a z^{2}+b z+c .
$$

Note that when determining the difference in gravity value at two different heights, the constant term, $c$, cancels. Uncertainties of the parameters $a$ and $b$ are derived from the variance-covariance matrix. Because the two instruments are analyzed simultaneously, any systematic difference between them appears as an increase in $a$ and $b$. Uncertainties in the height measurements (tier locations) are considered negligible. The parameters are listed (for all piers for completeness) in Table 2.

Finally, note that the gradient value is not expected to change at TMGO over the time-frame discussed. TMGO is located on a broad, flat, undisturbed expanse of land, and even unmodeled environmental factors like water table fluctuations will not cause a change in the value of the gradient.

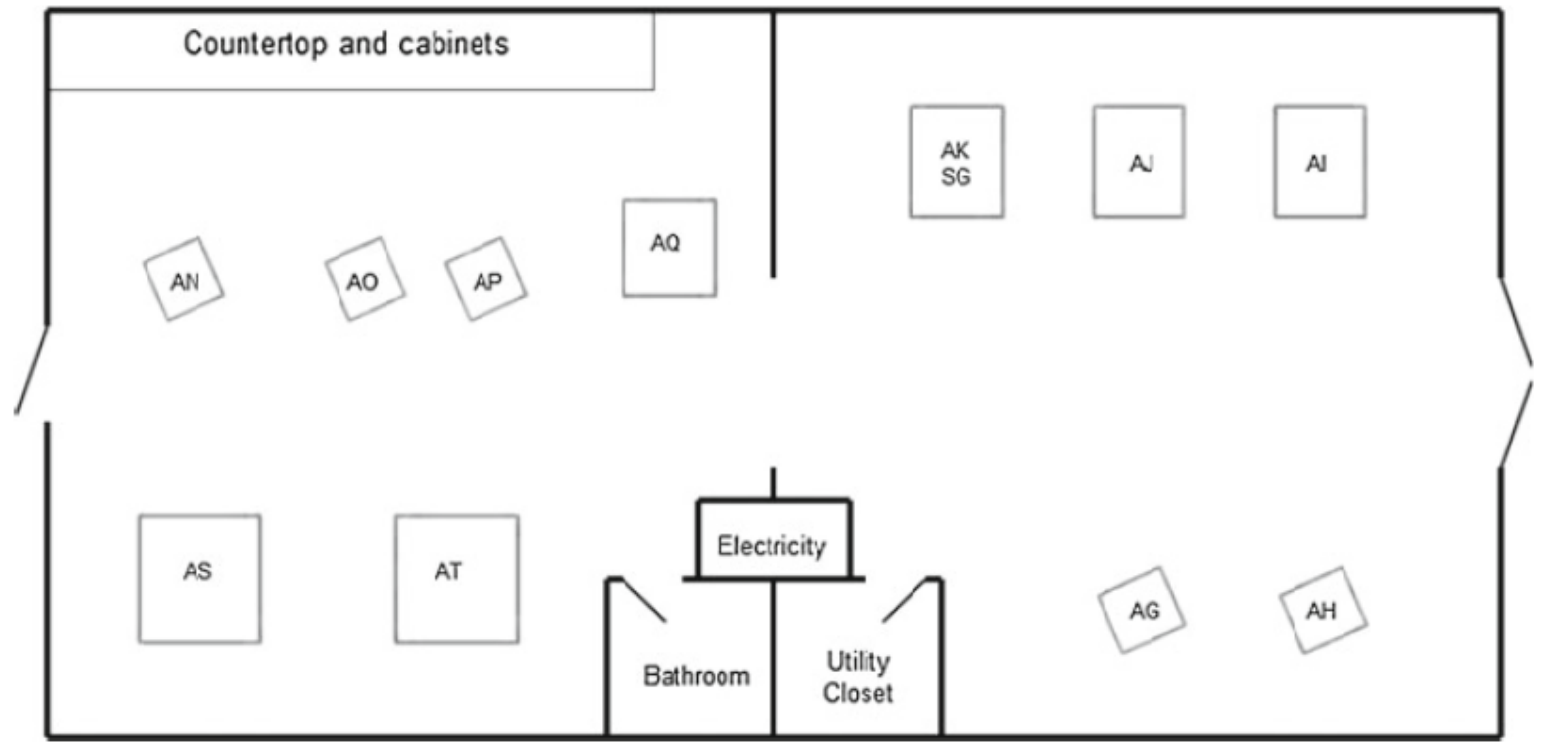

Figure 1. A schematic of the TMGO gravity piers. AK is permanently occupied by the SG, and only piers $A G, A H$, $A J, A Q, A S$, and $A T$ were used in the comparison. 
Table 2. Vertical gravity gradients at the TMGO piers (only $A G, A H, A J, A Q, A S$, and $A T$ were used for the comparison).

\begin{tabular}{cccccc}
\hline Site & $\begin{array}{c}a \\
/ \mu \mathrm{Gal} \mathrm{m}^{-2}\end{array}$ & $\begin{array}{c}\sigma_{a} \\
/ \mu \mathrm{Gal} \mathrm{m}^{-2}\end{array}$ & $\begin{array}{c}b \\
/ \mu \mathrm{Gal} \mathrm{m}^{-1}\end{array}$ & $\begin{array}{c}\sigma_{b} \\
/ \mu \mathrm{Gal} \mathrm{m}^{-1}\end{array}$ & $\begin{array}{c}\sigma_{a b} \\
/ \mu \mathrm{Gal}^{2} \mathrm{~m}^{-3}\end{array}$ \\
\hline $\mathrm{AG}$ & 4.6 & 1.3 & -322.3 & 1.7 & 2.2 \\
$\mathrm{AH}$ & 4.9 & 1.0 & -318.4 & 1.3 & 1.3 \\
$\mathrm{AI}$ & 3.6 & 1.7 & -310.4 & 2.1 & 3.6 \\
$\mathrm{AJ}$ & 1.1 & 1.1 & -316.1 & 1.5 & 1.7 \\
$\mathrm{AN}$ & 3.6 & 1.3 & -316.0 & 1.7 & 2.2 \\
$\mathrm{AO}$ & 3.3 & 1.2 & -319.4 & 1.6 & 1.9 \\
$\mathrm{AP}$ & 0.6 & 1.8 & -317.0 & 1.5 & 2.7 \\
$\mathrm{AQ}$ & 9.2 & 1.1 & -332.5 & 1.4 & 1.8 \\
$\mathrm{AS}$ & 8.5 & 3.0 & -330.0 & 4.0 & 12.0 \\
$\mathrm{AT}$ & 6.8 & 1.4 & -329.2 & 1.9 & 2.7 \\
\hline
\end{tabular}

The gravity difference between height $z_{1}$ and $z_{2}$ is given by:

$$
\Delta g\left(z_{1}-z_{2}\right)=g\left(z_{2}\right)-g\left(z_{1}\right)=a \times\left(z_{2}^{2}-z_{1}^{2}\right)+b \times\left(z_{2}-z_{1}\right)
$$

and the associated uncertainty

$$
\sigma_{\Delta g}^{2}=\left(z_{2}^{2}-z_{1}^{2}\right)^{2} \times \sigma_{a}^{2}+\left(z_{2}-z_{1}\right)^{2} \times \sigma_{b}^{2}+2 \times\left(z_{2}^{2}-z_{1}^{2}\right) \times\left(z_{2}-z_{1}\right) \times \sigma_{a b}
$$

The participants reported gravity results at the "effective measurement height", heff, of their respective gravimeters where the gravity value is least sensitive to the effect of the gradient [3] [4]. The gradient formula for that respective pier was then used to transfer the value to a final, common height of $125 \mathrm{~cm}$ (an approximate average of the effective measurement height for FG5 and FG5-X gravimeters).

The observed tidal parameters - used by all participants to correct for earth tides and ocean loading simultaneously - were provided by Olivier Francis, based on an analysis of SG CT-024. They are listed in Table 3 [5].

\section{Superconducting gravity meter measurements}

A GWR superconducting gravity meter, CT-024, was operated continuously throughout the comparison on pier AK, situated near the center of the absolute piers. Figure 2 displays the results after the earth tide, ocean loading, and atmospheric pressure effects have been removed. The resulting change in gravity, $\sim 1 \mu \mathrm{Gal}$ peak-to-peak, throughout the comparison was presumably observed by all gravity meters. This small, slow change in gravity is well within the systematic uncertainty of the absolute gravimeters, and its presence is thus neglected in the analysis. The mean times of absolute measurements are indicated by red circles. 
Table 3. Observed tidal parameters for TMGO from SG CT-024 via Olivier Francis.

\begin{tabular}{|l|l|l|l|c|}
\hline Wave & $\begin{array}{l}\text { Start Frequency } \\
\text { (cpd) }\end{array}$ & $\begin{array}{l}\text { Stop Frequency } \\
\text { (cpd) }\end{array}$ & $\begin{array}{l}\text { Amplitude } \\
\text { Factor }\end{array}$ & $\begin{array}{l}\text { Phase Lag } \\
\text { (degrees) }\end{array}$ \\
\hline DC & 0.000000 & 0.000001 & 1.00000 & 0.0000 \\
\hline long & 0.000002 & 0.249951 & 1.16000 & 0.0000 \\
\hline Q1 & 0.721500 & 0.906315 & 1.16052 & 1.1570 \\
\hline O1 & 0.921941 & 0.940487 & 1.16468 & 1.1775 \\
\hline NO1 & 0.958085 & 0.974188 & 1.15951 & 1.0326 \\
\hline P1 & 0.989049 & 0.998028 & 1.16539 & 1.1041 \\
\hline S1 & 0.999853 & 1.000147 & 1.49457 & 15.9599 \\
\hline K1 & 1.001825 & 1.003651 & 1.15452 & 1.1761 \\
\hline PSI1 & 1.005329 & 1.005623 & 1.30377 & 1.3908 \\
\hline PHI1 & 1.007595 & 1.011099 & 1.20411 & 0.6319 \\
\hline J1 & 1.013689 & 1.044800 & 1.18028 & 1.1094 \\
\hline OO1 & 1.064841 & 1.216397 & 1.18279 & 0.3491 \\
\hline 2N2 & 1.719381 & 1.872142 & 1.16806 & -0.4567 \\
\hline N2 & 1.888387 & 1.906462 & 1.15681 & -0.2398 \\
\hline M2 & 1.923766 & 1.942754 & 1.15945 & 0.1973 \\
\hline L2 & 1.958233 & 1.976926 & 1.16297 & 0.3812 \\
\hline S2 & 1.991787 & 2.002885 & 1.17172 & -0.5305 \\
\hline K2 & 2.003032 & 2.182843 & 1.17348 & -0.4844 \\
\hline M3 & 2.753244 & 3.081253 & 1.07285 & -0.2409 \\
\hline M4 & 3.381379 & 4.347615 & 1.03900 & 0.0000 \\
\hline & & & & \\
\hline
\end{tabular}

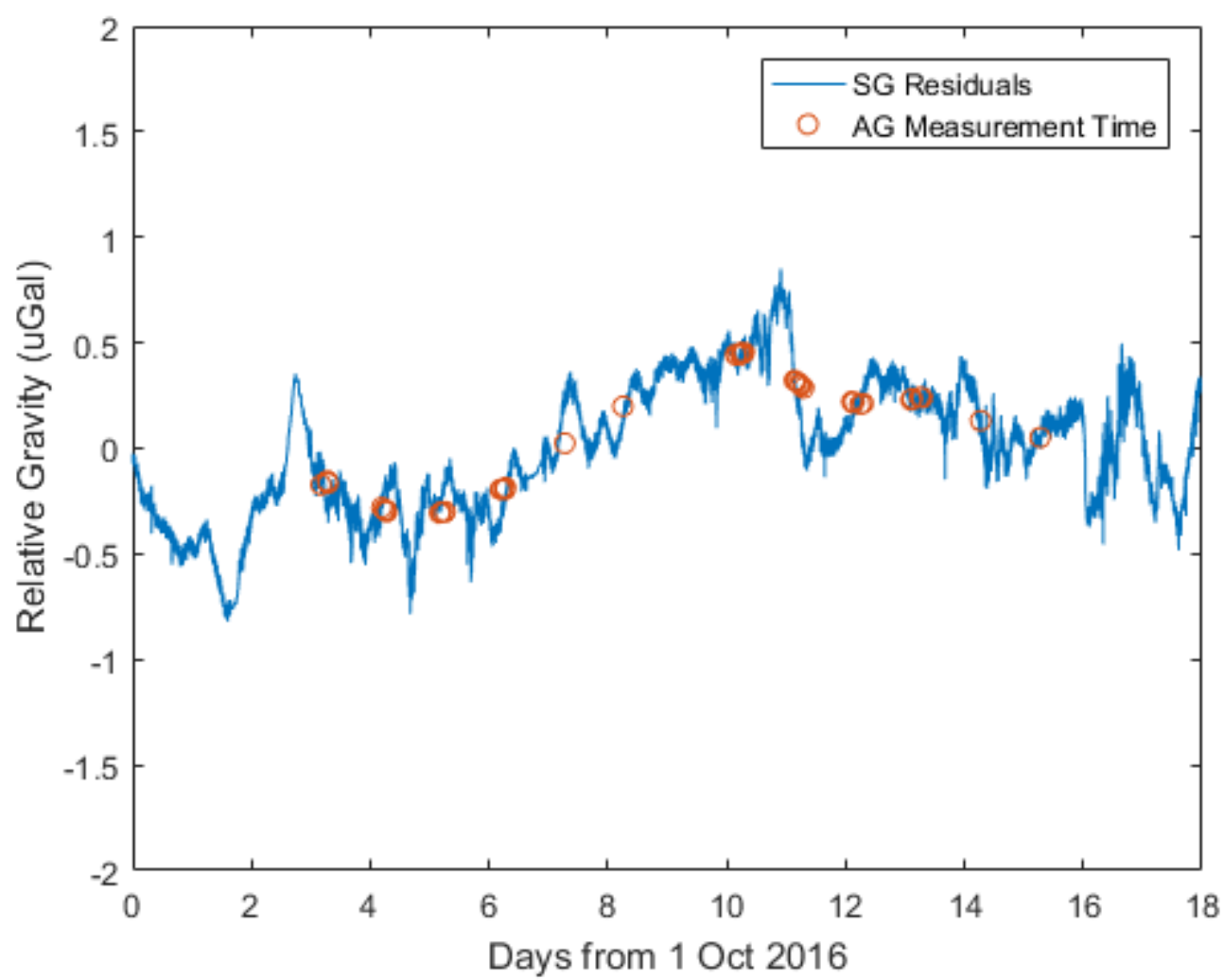

Figure 2. The output of the superconducting gravity meter, CT-024 with earth tides and barometric pressure effects removed (blue line). A maximum peak-to-peak signal of about $1.0 \mu \mathrm{Gal}$ is observed during the entire duration of the comparison. The red circles indicate the average times of each absolute gravity measurement. 


\section{Absolute gravity measurements}

Each participant was free to measure gravity over a duration of their choosing within a window of approximately 24 hours (before being required to move to the next scheduled pier). Table 4 lists the measurement schedule (NMI/DI gravimeters are shaded in pink). The schedule was designed to maximize the overlap of gravimeters, minimize the number of occupied piers, and prohibit reoccupations of the same pier by a single gravimeter [6]. Every gravimeter overlapped with every other gravimeter at least two times and no more than three times.

Table 4. Nominal pier occupation schedule for the comparison. Days 1-4 were Monday through Thursday nights (36 October, 2016), and days 5-8 were Monday through Thursday nights the following week (10-13, October, 2016). Due to real-time logistical constraints, not all instruments could observe on their scheduled date. The actual occupation times are listed in Table 5. (All instruments did observe at their scheduled location.)

\begin{tabular}{|l|l|l|l|l|l|l|l|l|}
\hline Pier\Day & $\mathbf{1}$ & $\mathbf{2}$ & $\mathbf{3}$ & $\mathbf{4}$ & $\mathbf{5}$ & $\mathbf{6}$ & $\mathbf{7}$ & $\mathbf{8}$ \\
\hline AG & FG5X-252 & FG5-301 & FG5-218 & FG5-234 & FG5-107 & FG5-204 & FG5X-102 & FG5-236 \\
\hline AH & FG5X-216 & FG5X-252 & FG5-301 & FG5-218 & FG5-105 & FG5-107 & FG5-204 & FG5X-302 \\
\hline AJ & FG5-238 & FG5X-216 & FG5X-252 & FG5-301 & FG5-236 & FG5-105 & FG5-107 & FG5X-102 \\
\hline AQ & FG5-234 & FG5-238 & FG5X-216 & FG5X-252 & FG5X-302 & FG5-236 & FG5-105 & FG5-204 \\
\hline AS & FG5-218 & FG5-234 & FG5-238 & FG5X-216 & FG5X-102 & FG5X-302 & FG5-236 & FG5-107 \\
\hline AT & FG5-301 & FG5-218 & FG5-234 & FG5-238 & FG5-204 & FG5X-102 & FG5X-302 & FG5-105 \\
\hline
\end{tabular}

Gravity was determined above each pier benchmark at heff unique to each gravimeter (and in principle, each gravimeter set up). Each raw gravity value is corrected for:

- Earth tides and ocean loading via a common set of observed tidal parameters [5]

- Barometric pressure changes from the nominal value of $826.74 \mathrm{mBar}$ using a common admittance factor of $-0.3 \mu \mathrm{Gal} / \mathrm{mbar}$ [7]

- Polar Motion using common values obtained from the Earth Rotation and Reference Systems Service (IERS) [8]

- Self attraction of the gravimeter itself [9] [10]

- Diffraction correction due to the finite width of the laser beam [11]

These raw gravity values were then transferred to a common height of $125 \mathrm{~cm}$ using the quadratic gradient parameters for each pier listed in Table 2. The gravimeter results are listed in Table 5. 


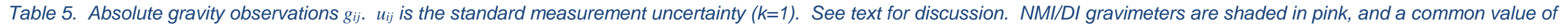
$979622000 \mu \mathrm{Gal}$ has been subtracted from each value. The days are UTC dates in October 2016.

\begin{tabular}{|c|c|c|c|c|c|c|c|c|c|c|c|}
\hline Gravimeter & Pier & $\begin{array}{l}\text { Gravity @ } \\
h_{\text {eff }}(\mu \text { Gal })\end{array}$ & $\begin{array}{l}\mathrm{h}_{\mathrm{eff}} \\
(\mathrm{m})\end{array}$ & $\begin{array}{l}\text { diffC } \\
(\mu \mathrm{Gal})\end{array}$ & $\begin{array}{l}\text { SAC } \\
(\mu \mathrm{Gal})\end{array}$ & $\begin{array}{l}\text { Start } \\
\text { Date }\end{array}$ & $\begin{array}{l}\text { Start } \\
\text { Time }\end{array}$ & $\begin{array}{l}\text { Stop } \\
\text { Date }\end{array}$ & $\begin{array}{l}\text { Stop } \\
\text { Time }\end{array}$ & $\begin{array}{l}\text { Gravity } \\
g_{i j}(\mu \mathrm{Gal})\end{array}$ & $\begin{array}{l}\text { Uncert } \\
u_{i j}(\mu \mathrm{Gal})\end{array}$ \\
\hline FG5X-252 & $A G$ & 737.8 & 1.311 & 1 & -1.2 & 8 & $21: 35$ & 9 & $14: 35$ & 756.7 & 2.2 \\
\hline FG5X-252 & $\mathrm{AH}$ & 739.3 & 1.311 & 1 & -1.2 & 4 & $21: 26$ & 5 & $15: 26$ & 758 & 2.2 \\
\hline FG5X-252 & AJ & 746.7 & 1.313 & 1 & -1.2 & 5 & $20: 40$ & 6 & $15: 40$ & 766.4 & 2.2 \\
\hline FG5X-252 & $\mathrm{AQ}$ & 741.5 & 1.309 & 1 & -1.2 & 6 & 19:03 & 7 & $15: 03$ & 759.7 & 2.2 \\
\hline FG5X-216 & $\mathrm{AH}$ & 749.1 & 1.27 & 1.2 & -1.4 & 3 & $17: 00$ & 4 & $15: 15$ & 755.2 & 2.38 \\
\hline FG5X-216 & AJ & 759.2 & 1.27 & 1.2 & -1.4 & 4 & $18: 00$ & 5 & $15: 30$ & 765.5 & 2.38 \\
\hline FG5X-216 & $\mathrm{AQ}$ & 750.9 & 1.27 & 1.2 & -1.4 & 5 & $17: 00$ & 6 & $16: 15$ & 757.1 & 2.38 \\
\hline FG5X-216 & AS & 745.8 & 1.27 & 1.2 & -1.4 & 6 & $18: 00$ & 7 & $15: 10$ & 752 & 2.38 \\
\hline FG5-238 & AJ & 777.8 & 1.217 & 1.05 & -1.2 & 3 & $22: 26$ & 4 & $15: 26$ & 767.4 & 1.85 \\
\hline FG5-238 & $\mathrm{AQ}$ & 771.3 & 1.218 & 1.05 & -1.2 & 4 & $21: 42$ & 5 & 13:41 & 761.3 & 1.87 \\
\hline FG5-238 & AS & 766.6 & 1.216 & 1.05 & -1.2 & 5 & $20: 22$ & 6 & $13: 22$ & 755.9 & 2.06 \\
\hline FG5-238 & AT & 766.7 & 1.214 & 1.05 & -1.2 & 6 & $21: 36$ & 7 & $15: 37$ & 755.5 & 1.9 \\
\hline FG5-234 & $A G$ & 768.9 & 1.215 & 1 & -1.5 & 7 & $0: 06$ & 7 & $12: 19$ & 758 & 1.99 \\
\hline FG5-234 & $\mathrm{AQ}$ & 769.7 & 1.214 & 1 & -1.5 & 4 & 1:06 & 4 & $12: 19$ & 758.6 & 1.97 \\
\hline FG5-234 & AS & 766.6 & 1.213 & 1 & -1.5 & 5 & $0: 06$ & 5 & $12: 19$ & 755.2 & 2.4 \\
\hline FG5-234 & AT & 768.3 & 1.211 & 1 & -1.5 & 6 & $0: 06$ & 6 & $12: 19$ & 756.2 & 2.01 \\
\hline FG5-218 & $A G$ & 773.6 & 1.205 & 1.20 & -1.36 & 6 & 1:05 & 5 & $12: 05$ & 759.6 & 1.87 \\
\hline FG5-218 & $\mathrm{AH}$ & 769.8 & 1.21 & 1.20 & -1.36 & 7 & $1: 05$ & 6 & 7:05 & 757.3 & 1.84 \\
\hline FG5-218 & AS & 772.2 & 1.205 & 1.20 & -1.36 & 8 & 1:05 & 7 & $12: 05$ & 758.2 & 2.14 \\
\hline FG5-218 & AT & 776.9 & 1.201 & 1.20 & -1.36 & 5 & 1:05 & 4 & $12: 05$ & 761.5 & 2.03 \\
\hline FG5-301 & AG & 764.4 & 1.22 & 2 & -1.43 & 4 & $21: 23$ & 5 & $15: 39$ & 755.1 & 2.33 \\
\hline FG5-301 & $\mathrm{AH}$ & 767.1 & 1.22 & 2 & -1.43 & 5 & 20:33 & 6 & $15: 49$ & 758 & 2.32 \\
\hline FG5-301 & AJ & 776.3 & 1.22 & 2 & -1.43 & 6 & $21: 16$ & 7 & $15: 33$ & 766.9 & 2.33 \\
\hline FG5-301 & AT & 765.1 & 1.22 & 2 & -1.43 & 7 & $21: 57$ & 8 & $15: 14$ & 755.8 & 2.34 \\
\hline FG5X-102 & AG & 748.1 & 1.286 & 1.05 & -1.2 & 12 & 15:01 & 13 & 14:01 & 759.2 & 1.84 \\
\hline FG5X-102 & AJ & 754.9 & 1.285 & 1.05 & -1.2 & 13 & $14: 23$ & 14 & $14: 23$ & 765.8 & 1.85 \\
\hline FG5X-102 & AS & 743.8 & 1.282 & 1.05 & -1.2 & 10 & $20: 41$ & 11 & $14: 41$ & 753.7 & 1.87 \\
\hline
\end{tabular}




\begin{tabular}{|l|l|r|r|r|r|r|r|r|r|r|r|}
\hline FG5X-102 & AT & 745 & 1.281 & 1.05 & -1.2 & 11 & $20: 50$ & 12 & $13: 50$ & 754.7 & 1.85 \\
\hline FG5-204 & AG & 764.1 & 1.231 & 1.98 & -1.23 & 12 & $0: 01$ & 12 & $11: 46$ & 758.2 & 1.83 \\
\hline FG5-204 & AH & 763 & 1.232 & 1.98 & -1.23 & 13 & $0: 01$ & 13 & $11: 46$ & 757.5 & 1.82 \\
\hline FG5-204 & AQ & 763.1 & 1.23 & 1.98 & -1.23 & 14 & $0: 06$ & 14 & $11: 51$ & 756.9 & 1.83 \\
\hline FG5-204 & AT & 765.5 & 1.227 & 1.98 & -1.23 & 11 & $0: 11$ & 11 & $11: 56$ & 758.3 & 2.13 \\
\hline FG5-107 & AG & 764.3 & 1.225 & 1.05 & -1.2 & 10 & $21: 01$ & 11 & $14: 01$ & 756.5 & 1.88 \\
\hline FG5-107 & AH & 763 & 1.228 & 1.05 & -1.2 & 11 & $16: 23$ & 12 & $14: 23$ & 756.2 & 1.85 \\
\hline FG5-107 & AJ & 775.8 & 1.227 & 1.05 & -1.2 & 12 & $16: 23$ & 13 & $14: 23$ & 768.5 & 1.87 \\
\hline FG5-107 & AS & 763.8 & 1.226 & 1.05 & -1.2 & 13 & $14: 23$ & 14 & $14: 23$ & 756.3 & 2.04 \\
\hline FG5-105 & AH & 756.6 & 1.242 & 0.9 & -1.1 & 10 & $18: 32$ & 11 & $12: 33$ & 754.2 & 1.71 \\
\hline FG5-105 & AJ & 770 & 1.237 & 0.9 & -1.1 & 11 & $17: 48$ & 12 & $13: 48$ & 765.9 & 1.72 \\
\hline FG5-105 & AQ & 758 & 1.237 & 0.9 & -1.1 & 12 & $17: 00$ & 13 & $13: 00$ & 754 & 2.51 \\
\hline FG5-105 & AT & 758.8 & 1.235 & 0.9 & -1.1 & 13 & $17: 00$ & 14 & $13: 00$ & 754.1 & 1.74 \\
\hline FG5-236 & AG & 761.4 & 1.226 & 0.82 & -1.2 & 14 & $1: 04$ & 14 & $12: 49$ & 754 & 1.99 \\
\hline FG5-236 & AJ & 773.3 & 1.221 & 0.82 & -1.2 & 11 & $1: 08$ & 11 & $12: 53$ & 764.2 & 2.02 \\
\hline FG5-236 & AQ & 764.4 & 1.223 & 0.82 & -1.2 & 12 & $1: 07$ & 12 & $12: 52$ & 756.1 & 1.98 \\
\hline FG5-236 & AS & 762.4 & 1.217 & 0.82 & -1.2 & 13 & $1: 08$ & 13 & $12: 53$ & 752.3 & 2.17 \\
\hline FG5X-302 & AH & 744.9 & 1.288 & 1.05 & -1.2 & 14 & $21: 16$ & 15 & $15: 47$ & 756.4 & 1.81 \\
\hline FG5X-302 & AQ & 746 & 1.293 & 1.05 & -1.2 & 10 & $18: 37$ & 11 & $13: 37$ & 759.1 & 1.81 \\
\hline FG5X-302 & AS & 742.2 & 1.285 & 1.05 & -1.2 & 11 & $18: 14$ & 12 & $14: 13$ & 753 & 1.82 \\
\hline FG5X-302 & AT & 742.5 & 1.285 & 1.05 & -1.2 & 15 & $19: 04$ & 16 & $18: 04$ & 753.4 & 1.81 \\
\hline
\end{tabular}




\section{Comparison Analysis Methods}

Following Koo and Clare [12], the gravity values for each gravimeter on each pier are expressed as

$$
g_{i j}=g_{j}+\delta_{i}+\varepsilon_{i j}
$$

where $g_{i j}$ is the gravity value measured on pier $j$ by gravimeter $i$ as given in Table $5, g_{j}$ is the true (unknown) gravity value at pier $j, \delta_{i}$ is the true (unknown) bias of gravimeter $i$, and $\varepsilon_{i j}$ is the measurement error. A variance weighted least squares analysis (LSA) is performed to give the best estimates of the pier gravity Reference Values $g_{j}$ and the gravimeter biases $\delta_{i}$. Since we do not consider correlations among the gravity measurements, the input (or measurement) covariance matrix $\boldsymbol{V}$ is diagonal with diagonal elements $u_{i j}{ }^{2}$ where $u_{i j}$ is given in Table 5. Thus the corresponding weight matrix $\boldsymbol{W}=\boldsymbol{V}^{-1}$ is also diagonal with diagonal elements $w_{i j}=1 / u_{i j}{ }^{2}$. The set of equations is ill defined with an infinite number of solutions, so an additional constraint on the weighted sum of the biases is imposed:

$$
\sum_{i=1}^{n} \bar{w}_{i} \delta_{i}=d
$$

where $d$ is the linking converter for the KCRVs. The normalized variance weights $\bar{w}_{i}$ have the condition that

$$
\sum_{i=1}^{n} \bar{w}_{i}=1
$$

and are defined as

$$
\bar{w}_{i}=\frac{w_{i}}{\sum_{i=1}^{n} w_{i}}
$$

where $w_{i}=1 / u_{i}^{2}$ and $u_{i}$ is the root mean square of $u_{i j}$ given in Table 5 for gravimeter $i$. Initially $d$ is taken to be zero. By definition, only NMI and DI gravimeters can contribute to the KCRVs. Therefore the only nonzero weights are 0.224 for FG5X-252, 0.192 for FG5X-216, 0.299 for FG5204, and 0.286 for FG5-105. The link of the KCRVs to CCM.G-K2 is then provided by the DoE of FG5X-216 from CCM.G-K2 [1] through EURAMET.M.G-K2 [2].

Results for the Pilot Study where all participating gravimeters are treated as equivalent with nonzero normalized weights are given in Appendix A.

\section{Results}

\subsection{Initial results}

For the initial solution, all measurements presented by the operators as given in Table 5 were included in the LSA. For 31 degrees of freedom (49 input data, 18 unknowns), the chi square statistic is $\chi^{2}=16.3$ with probability $p(16.3 \mid 31)=0.99$ and a Birge ratio of $R_{\mathrm{B}}=\sqrt{16.3 / 31}=0.73$, indicating a high level of consistency for the input data. The gravimeter biases $(\delta)$ and pier Reference Values $(g)$ are presented in Table 6 and Figure 3. 
Table 6. Initial biases $(\delta)$ of NMI/DIs (pink) and non-NMI/DIs and pier Reference Values $(\mathrm{g})$ at a height of $125 \mathrm{~cm}$ of the comparison using all the reported absolute measurements. The constant value $979622000.0 \mu \mathrm{Gal}$ is subtracted from the Reference Values, $U$ is the expanded standard uncertainty at 95\% confidence ( $k=2)$.

\begin{tabular}{|l|c|c|}
\hline Gravimeter & $\delta / \mu G a l$ & $U / \mu$ Gal \\
\hline FG5X-252 & 1.10 & 1.95 \\
\hline FG5X-216 & -1.10 & 2.18 \\
\hline FG5-238 & 1.63 & 2.24 \\
\hline FG5-234 & 1.12 & 2.39 \\
\hline FG5-218 & 3.64 & 2.28 \\
\hline FG5-301 & 0.52 & 2.58 \\
\hline FG5X-102 & 0.37 & 2.22 \\
\hline FG5-204 & 1.29 & 1.62 \\
\hline FG5-107 & 1.18 & 2.23 \\
\hline FG5-105 & -1.47 & 1.63 \\
\hline FG5-236 & -0.69 & 2.34 \\
\hline FG5X-302 & -0.29 & 2.14 \\
\hline
\end{tabular}

\begin{tabular}{|l|c|c|}
\hline Pier & $g / \mu \mathrm{Gal}$ & $U / \mu \mathrm{Gal}$ \\
\hline AG & 756.29 & 1.75 \\
\hline AH & 755.86 & 1.57 \\
\hline AJ & 766.36 & 1.70 \\
\hline AQ & 757.90 & 1.66 \\
\hline AS & 754.08 & 1.90 \\
\hline AT & 755.23 & 1.73 \\
\hline
\end{tabular}

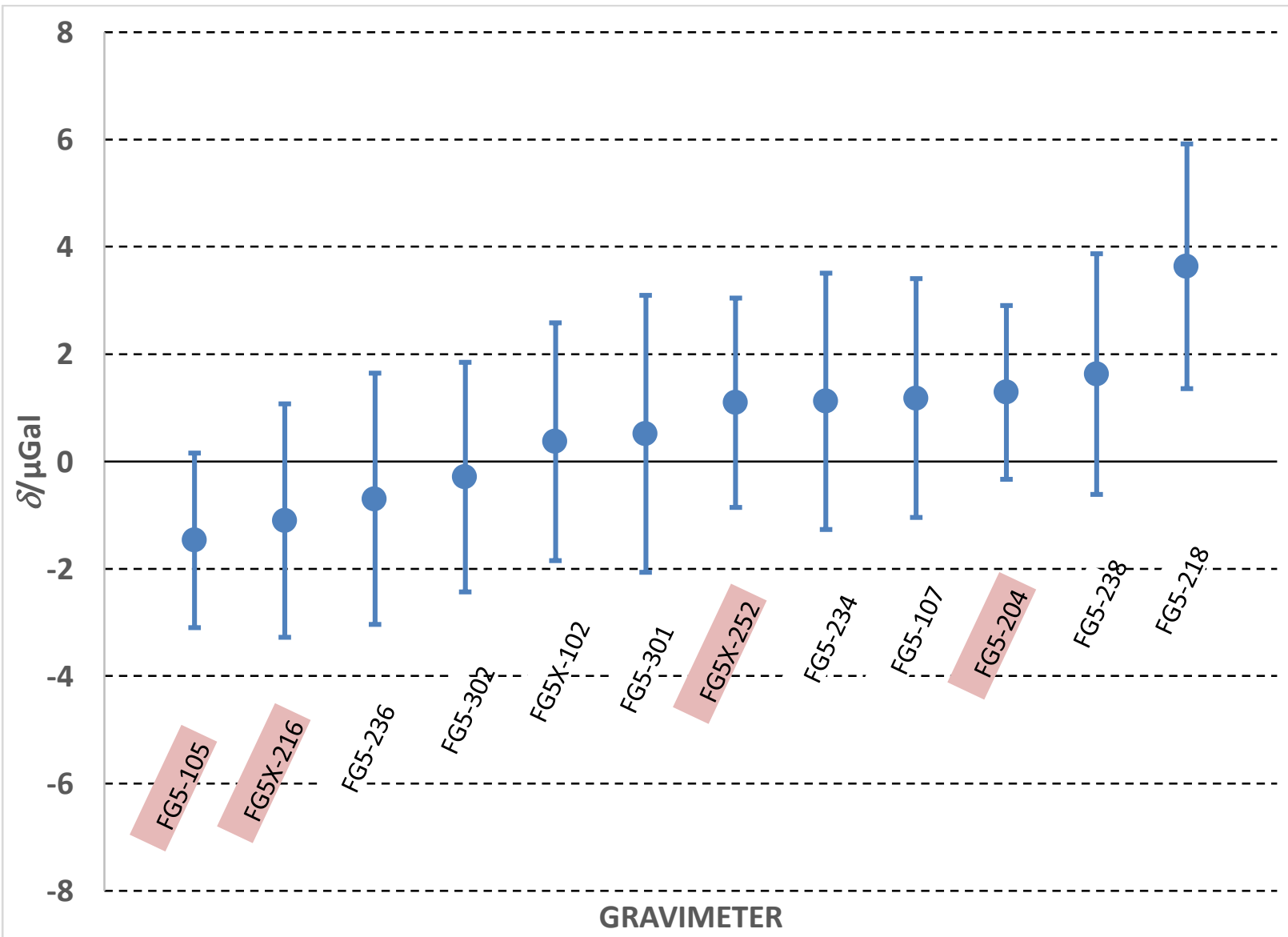

Figure 3. Initial biases $\delta$ of the gravimeters from the initial weighted LSA. Gravimeters of NMI/DIs are highlighted in pink. The error bars are the expanded standard uncertainties $(k=2)$ from the weighted LSA and are listed in Table 6. 


\subsection{Consistency of input data}

The consistency of the input data is investigated by calculating the normalized residuals $R_{i j}$ from the LSA,

$$
R_{i j}=\frac{\left(g_{i j}-g_{j}\right)}{U_{i j}},
$$

where $U_{i j}$ is the expanded uncertainty $(\mathrm{k}=2)$ of the measured value in Table 5. A less stringent test is to calculate the ratio of the difference between measured values of gravity and the reference value to the uncertainty of the difference, called the compatibility index $E_{i j}$,

$$
E_{i j}=\frac{\left(g_{i j}-g_{j}\right)}{\sqrt{U_{i j}^{2}+U_{j}^{2}}},
$$

where $U_{j}$ is the expanded standard uncertainty $(\mathrm{k}=2)$ of the reference value $g_{j}$ from the weighted LSA in Table 6. An absolute value of $R_{i j}$ or $E_{i j}$ larger than 1 indicates inconsistency at the 95\% confidence level for the given test. Values of $R_{i j}$ and $E_{i j}$ are given in Table 7. Only one of the input data has an $R_{i j}$ or $E_{i j}$ value larger than 1, with FG5-218 on pier AT at $R_{i j}=1.54$ and $E_{i j}=1.42$. Since FG5-218 does not represent an NMI or DI, this value was omitted in the final analysis without further consideration.

Table 7. Consistency of input data: Comparison of measured gravity values $g_{i j}$ (along with expanded standard uncertainties $U_{i j}$ ) with reference values $g_{j}$ (along with expanded standard uncertainties $U_{j}$ ) by means of $R_{i j}$ and $E_{i j}$. NMI/DI gravimeters are in pink. The constant value $979622000.0 \mu \mathrm{Gal}$ has been subtracted from the gravity measurements. $R_{i j}$ and $E_{i j}$ values larger than 1 are in yellow.

\begin{tabular}{|l|c|c|c|c|c|c|c|c|}
\hline Gravimeter & Pier & $\begin{array}{c}g_{i j} \\
/ \mu \mathrm{Gal}\end{array}$ & $\begin{array}{c}U_{i j} \\
/ \mu \mathrm{Gal}\end{array}$ & $\begin{array}{c}g_{j} \\
/ \mu \mathrm{Gal}\end{array}$ & $\begin{array}{c}U_{j} \\
/ \mu \mathrm{Gal}\end{array}$ & $\begin{array}{c}g_{i j} g_{j} \\
/ \mu \mathrm{Gal}\end{array}$ & $R_{i j}$ & $E_{i j}$ \\
\hline FG5X-252 & AG & 756.70 & 4.40 & 756.29 & 1.75 & 0.41 & 0.09 & 0.09 \\
FG5X-252 & AH & 758.00 & 4.40 & 755.86 & 1.57 & 2.14 & 0.49 & 0.46 \\
FG5X-252 & AJ & 766.40 & 4.40 & 766.36 & 1.70 & 0.04 & 0.01 & 0.01 \\
FG5X-252 & AQ & 759.70 & 4.40 & 757.90 & 1.66 & 1.80 & 0.41 & 0.38 \\
\hline FG5X-216 & AH & 755.20 & 4.76 & 755.86 & 1.57 & -0.66 & -0.14 & -0.13 \\
FG5X-216 & AJ & 765.50 & 4.76 & 766.36 & 1.70 & -0.86 & -0.18 & -0.17 \\
FG5X-216 & AQ & 757.10 & 4.76 & 757.90 & 1.66 & -0.80 & -0.17 & -0.16 \\
FG5X-216 & AS & 752.00 & 4.76 & 754.08 & 1.90 & -2.08 & -0.44 & -0.41 \\
\hline FG5-238 & AJ & 767.40 & 3.70 & 766.36 & 1.70 & 1.04 & 0.28 & 0.25 \\
FG5-238 & AQ & 761.30 & 3.74 & 757.90 & 1.66 & 3.40 & 0.91 & 0.83 \\
FG5-238 & AS & 755.90 & 4.12 & 754.08 & 1.90 & 1.82 & 0.44 & 0.40 \\
FG5-238 & AT & 755.50 & 3.80 & 755.23 & 1.73 & 0.27 & 0.07 & 0.06 \\
\hline FG5-234 & AG & 758.00 & 3.98 & 756.29 & 1.75 & 1.71 & 0.43 & 0.39 \\
FG5-234 & AQ & 758.60 & 3.94 & 757.90 & 1.66 & 0.70 & 0.18 & 0.16 \\
FG5-234 & AS & 755.20 & 4.80 & 754.08 & 1.90 & 1.12 & 0.23 & 0.22 \\
FG5-234 & AT & 756.20 & 4.02 & 755.23 & 1.73 & 0.97 & 0.24 & 0.22 \\
\hline FG5-218 & AG & 759.60 & 3.74 & 756.29 & 1.75 & 3.31 & 0.88 & 0.80 \\
FG5-218 & AH & 757.30 & 3.68 & 755.86 & 1.57 & 1.44 & 0.39 & 0.36
\end{tabular}




\begin{tabular}{|l|c|c|c|c|c|c|c|c|} 
FG5-218 & AS & 758.20 & 4.28 & 754.08 & 1.90 & 4.12 & 0.96 & 0.88 \\
FG5-218 & AT & 761.50 & 4.06 & 755.23 & 1.73 & 6.27 & 1.54 & 1.42 \\
\hline FG5-301 & AG & 755.10 & 4.66 & 756.29 & 1.75 & -1.19 & -0.26 & -0.24 \\
FG5-301 & AH & 758.00 & 4.64 & 755.86 & 1.57 & 2.14 & 0.46 & 0.44 \\
FG5-301 & AJ & 766.90 & 4.66 & 766.36 & 1.70 & 0.54 & 0.12 & 0.11 \\
FG5-301 & AT & 755.80 & 4.68 & 755.23 & 1.73 & 0.57 & 0.12 & 0.11 \\
\hline FG5X-102 & AG & 759.20 & 3.68 & 756.29 & 1.75 & 2.91 & 0.79 & 0.71 \\
FG5X-102 & AJ & 765.80 & 3.70 & 766.36 & 1.70 & -0.56 & -0.15 & -0.14 \\
FG5X-102 & AS & 753.70 & 3.74 & 754.08 & 1.90 & -0.38 & -0.10 & -0.09 \\
FG5X-102 & AT & 754.70 & 3.70 & 755.23 & 1.73 & -0.53 & -0.14 & -0.13 \\
\hline FG5-204 & AG & 758.20 & 3.66 & 756.29 & 1.75 & 1.91 & 0.52 & 0.47 \\
FG5-204 & AH & 757.50 & 3.64 & 755.86 & 1.57 & 1.64 & 0.45 & 0.41 \\
FG5-204 & AQ & 756.90 & 3.66 & 757.90 & 1.66 & -1.00 & -0.27 & -0.25 \\
FG5-204 & AT & 758.30 & 4.26 & 755.23 & 1.73 & 3.07 & 0.72 & 0.67 \\
\hline FG5-107 & AG & 756.50 & 3.76 & 756.29 & 1.75 & 0.21 & 0.05 & 0.05 \\
FG5-107 & AH & 756.20 & 3.70 & 755.86 & 1.57 & 0.34 & 0.09 & 0.09 \\
FG5-107 & AJ & 768.50 & 3.74 & 766.36 & 1.70 & 2.14 & 0.57 & 0.52 \\
FG5-107 & AS & 756.30 & 4.08 & 754.08 & 1.90 & 2.22 & 0.54 & 0.49 \\
\hline FG5-105 & AH & 754.20 & 3.42 & 755.86 & 1.57 & -1.66 & -0.48 & -0.44 \\
FG5-105 & AJ & 765.90 & 3.44 & 766.36 & 1.70 & -0.46 & -0.13 & -0.12 \\
FG5-105 & AQ & 754.00 & 5.02 & 757.90 & 1.66 & -3.90 & -0.78 & -0.74 \\
FG5-105 & AT & 754.10 & 3.48 & 755.23 & 1.73 & -1.13 & -0.33 & -0.29 \\
\hline FG5-236 & AG & 754.60 & 3.98 & 756.29 & 1.75 & -1.69 & -0.43 & -0.39 \\
FG5-236 & AJ & 765.70 & 4.02 & 766.36 & 1.70 & -0.66 & -0.17 & -0.15 \\
FG5-236 & AQ & 757.30 & 3.96 & 757.90 & 1.66 & -0.60 & -0.15 & -0.14 \\
FG5-236 & AS & 754.40 & 4.28 & 754.08 & 1.90 & 0.32 & 0.08 & 0.07 \\
\hline FG5X-302 & AH & 756.40 & 3.62 & 755.86 & 1.57 & 0.54 & 0.15 & 0.14 \\
FG5X-302 & AQ & 759.10 & 3.62 & 757.90 & 1.66 & 1.20 & 0.33 & 0.30 \\
FG5X-302 & AS & 753.00 & 3.64 & 754.08 & 1.90 & -1.08 & -0.30 & -0.26 \\
FG5X-302 & AT & 753.40 & 3.62 & 755.23 & 1.73 & -1.83 & -0.51 & -0.46 \\
\hline
\end{tabular}

\subsection{Linking converter}

The linking converter of SIM.M.G-K1 to CCM.G-K2 is through the DoE of $-0.4 \mu \mathrm{Gal} \pm 2.65$ $\mu \mathrm{Gal}(\mathrm{k}=1)$ determined for the DI gravimeter FG5X-216 during CCM.G-K2 [1] through EURAMET.M.G-K2 [2]. The final result of FG5X-216 for SIM.M.G.K1 with $d$ set to zero and the datum of FG5-218 on pier AT removed is $-1.15 \mu \mathrm{Gal} \pm 1.09 \mu \mathrm{Gal}$. Therefore the linking converter is $d=0.75 \mu \mathrm{Gal} \pm 2.86 \mu \mathrm{Gal}(\mathrm{k}=1)( \pm 5.73 \mu \mathrm{Gal} \mathrm{k}=2)$.

Since the linking converter of SIM.M.G-K1 to CCM.G-K2 relies on a single DI, a subsequent verification is performed by calculating a linking converter of SIM.M.G-K1 to CCM.G-K1 through the DoE of NMI gravimeter FG5-105 of $-1.0 \mu \mathrm{Gal} \pm 2.7 \mu \mathrm{Gal}(\mathrm{k}=1)$ for CCM.G-K1. The final result of FG5-105 for SIM.M.G-K1 with $d$ set to zero and the datum of FG5-218 on pier AT removed is $-1.39 \mu \mathrm{Gal} \pm 0.81 \mu \mathrm{Gal}$. Therefore the linking converter for SIM.M.G-K1 to CCM.G$\mathrm{K} 1$ would be $d=0.39 \mu \mathrm{Gal} \pm 2.82 \mu \mathrm{Gal}(\mathrm{k}=1)( \pm 5.64 \mu \mathrm{Gal} \mathrm{k}=2)$. The difference of $0.36 \mu \mathrm{Gal}$ between the two links are well within the uncertainties of the links, adding confidence in the stability of the link. 


\subsection{Final results}

A final LSA was performed excluding the measurement of the FG5-218 at pier AT and with $d=0.75 \mu \mathrm{Gal}$ to obtain the best estimates for the KCRVs, given in Table 8 . The expanded standard uncertainty $U_{j}$ includes the expanded standard uncertainty of $5.73 \mu \mathrm{Gal}$ from the linking converter. For 30 degrees of freedom (48 input data, 18 unknowns), the chi square statistic is $\chi^{2}=13.8$ with probability $p(13.8 \mid 30)=0.99$ and a Birge ratio of $R_{\mathrm{B}}=\sqrt{13.8 / 30}=0.68$, indicating a very high level of consistency for the input data. Following Jiang et al. [13], the DoEs are the weighted average difference between the measurements of a gravimeter $i$ and the KCRVs at given site $j$,

$$
D_{i}=\left[\sum w_{i j}\left(g_{i j}-g_{j}\right)\right] / \sum w_{i j}
$$

where the weights $w_{i j}=1 / U_{D i j}{ }^{2}$ and $U_{D i j}$ is the expanded uncertainty of the difference $g_{i j}-g_{j}$. The differences, expanded uncertainties, and DoEs are shown in Table 9. $U_{D i}$ is the expanded uncertainty of the weighted differences. The official DoE results for comparison SIM.M.G-K1 are given in Table 10 and Figure 4. All the gravimeters are in excellent equivalence.

Table 8. Key Comparison Reference Values (KCRVs) linked to the CCM.G.K-2 using linking converter of $(0.72 \pm 5.73) \mu \mathrm{Gal}(\mathrm{k}=2)$ related to DI gravimeter FG5X-216. The constant value $979622000.0 \mu \mathrm{Gal}$ is subtracted from the KCRVs. $U$ is the expanded standard uncertainty at $95 \%$ confidence computed as the root mean square of the expanded standard uncertainty from the LSA and the expanded uncertainty of the linking converter.

\begin{tabular}{|c|c|c|}
\hline \multicolumn{3}{|c|}{$\begin{array}{c}\text { Official Key Comparison } \\
\text { Results }\end{array}$} \\
\hline Pier & KCRV/ $\mu \mathrm{Gal}$ & $U / \mu \mathrm{Gal}$ \\
\hline AG & 755.68 & 5.99 \\
\hline AH & 755.24 & 5.94 \\
\hline AJ & 765.61 & 5.98 \\
\hline AQ & 757.14 & 5.97 \\
\hline AS & 753.43 & 6.04 \\
\hline AT & 754.09 & 6.01 \\
\hline
\end{tabular}

Table 9. DoEs of NMI/DIs (pink) and non-NMI/DIs. $g_{i j}$ are the measured gravity values transferred to $125 \mathrm{~cm}$ with expanded uncertainty $U_{i j} . g_{j}$ are the KCRVs with associated expanded ( $\left.k=2\right)$ uncertainties $U_{j}$ given in Table 8 . $U_{D i j}$ is the expanded uncertainty of differences $g_{i j} g_{j} . D_{i}$ is the final DoE computed according to Eq. 10 along with the expanded uncertainty $U_{D i}$. The constant value $979622000.0 \mu \mathrm{Gal}$ was subtracted from the gravity measurements.

\begin{tabular}{|l|c|c|c|c|c|c|c|c|c|}
\hline Gravimeter & Pier & $\begin{array}{c}g_{i j} \\
/ \mu \mathrm{Gal}\end{array}$ & $\begin{array}{c}U_{i j} \\
/ \mu \mathrm{Gal}\end{array}$ & $\begin{array}{c}g_{j} \\
/ \mu \mathrm{Gal}\end{array}$ & $\begin{array}{c}U_{j} \\
/ \mu \mathrm{Gal}\end{array}$ & $\begin{array}{c}g_{i j} g_{j} \\
/ \mu \mathrm{Gal}\end{array}$ & $\begin{array}{c}U_{D i j} \\
/ \mu \mathrm{Gal}\end{array}$ & $\begin{array}{c}D_{i} \\
/ \mu \mathrm{Gal}\end{array}$ & $\begin{array}{c}U_{D i} \\
/ \mu \mathrm{Gal}\end{array}$ \\
\hline FG5X-252 & $\mathrm{AG}$ & 756.70 & 4.40 & 755.68 & 5.99 & 1.02 & 7.44 & 1.79 & 3.71 \\
FG5X-252 & $\mathrm{AH}$ & 758.00 & 4.40 & 755.24 & 5.94 & 2.76 & 7.39 & & \\
FG5X-252 & $\mathrm{AJ}$ & 766.40 & 4.40 & 765.61 & 5.98 & 0.79 & 7.42 & & \\
FG5X-252 & $\mathrm{AQ}$ & 759.70 & 4.40 & 757.14 & 5.97 & 2.56 & 7.41 & & \\
\hline FG5X-216 & $\mathrm{AH}$ & 755.20 & 4.76 & 755.24 & 5.94 & -0.04 & 7.61 & -0.40 & 3.82 \\
FG5X-216 & $\mathrm{AJ}$ & 765.50 & 4.76 & 765.61 & 5.98 & -0.11 & 7.64 & & \\
FG5X-216 & $\mathrm{AQ}$ & 757.10 & 4.76 & 757.14 & 5.97 & -0.04 & 7.63 & & \\
FG5X-216 & $\mathrm{AS}$ & 752.00 & 4.76 & 753.43 & 6.04 & -1.43 & 7.69 & & \\
\hline FG5-238 & $\mathrm{AJ}$ & 767.40 & 3.70 & 765.61 & 5.98 & 1.79 & 7.03 & 2.46 & 3.56
\end{tabular}




\begin{tabular}{|c|c|c|c|c|c|c|c|c|c|}
\hline FG5-238 & $A Q$ & 761.30 & 3.74 & 757.14 & 5.97 & 4.16 & 7.04 & & \\
\hline FG5-238 & AS & 755.90 & 4.12 & 753.43 & 6.04 & 2.47 & 7.31 & & \\
\hline FG5-238 & AT & 755.50 & 3.80 & 754.09 & 6.01 & 1.41 & 7.11 & & \\
\hline FG5-234 & $A G$ & 758.00 & 3.98 & 755.68 & 5.99 & 2.32 & 7.20 & \multirow[t]{4}{*}{1.92} & \multirow[t]{4}{*}{3.66} \\
\hline FG5-234 & $A Q$ & 758.60 & 3.94 & 757.14 & 5.97 & 1.46 & 7.15 & & \\
\hline FG5-234 & AS & 755.20 & 4.80 & 753.43 & 6.04 & 1.77 & 7.71 & & \\
\hline FG5-234 & AT & 756.20 & 4.02 & 754.09 & 6.01 & 2.11 & 7.23 & & \\
\hline FG5-218 & $A G$ & 759.60 & 3.74 & 755.68 & 5.99 & 3.92 & 7.07 & \multirow[t]{3}{*}{3.54} & \multirow[t]{3}{*}{4.13} \\
\hline FG5-218 & $\mathrm{AH}$ & 757.30 & 3.68 & 755.24 & 5.94 & 2.06 & 6.99 & & \\
\hline FG5-218 & AS & 758.20 & 4.28 & 753.43 & 6.04 & 4.77 & 7.40 & & \\
\hline FG5-301 & $A G$ & 755.10 & 4.66 & 755.68 & 5.99 & -0.58 & 7.59 & \multirow[t]{4}{*}{1.30} & \multirow[t]{4}{*}{3.79} \\
\hline FG5-301 & $\mathrm{AH}$ & 758.00 & 4.64 & 755.24 & 5.94 & 2.76 & 7.54 & & \\
\hline FG5-301 & AJ & 766.90 & 4.66 & 765.61 & 5.98 & 1.29 & 7.58 & & \\
\hline FG5-301 & AT & 755.80 & 4.68 & 754.09 & 6.01 & 1.71 & 7.61 & & \\
\hline FG5X-102 & $A G$ & 759.20 & 3.68 & 755.68 & 5.99 & 3.52 & 7.03 & \multirow[t]{4}{*}{1.15} & \multirow[t]{4}{*}{3.53} \\
\hline FG5X-102 & AJ & 765.80 & 3.70 & 765.61 & 5.98 & 0.19 & 7.03 & & \\
\hline FG5X-102 & AS & 753.70 & 3.74 & 753.43 & 6.04 & 0.27 & 7.10 & & \\
\hline FG5X-102 & AT & 754.70 & 3.70 & 754.09 & 6.01 & 0.61 & 7.05 & & \\
\hline FG5-204 & $A G$ & 758.20 & 3.66 & 755.68 & 5.99 & 2.52 & 7.02 & \multirow[t]{4}{*}{2.14} & \multirow[t]{4}{*}{3.54} \\
\hline FG5-204 & $\mathrm{AH}$ & 757.50 & 3.64 & 755.24 & 5.94 & 2.26 & 6.97 & & \\
\hline FG5-204 & $\mathrm{AQ}$ & 756.90 & 3.66 & 757.14 & 5.97 & -0.24 & 7.00 & & \\
\hline FG5-204 & AT & 758.30 & 4.26 & 754.09 & 6.01 & 4.21 & 7.36 & & \\
\hline FG5-107 & $A G$ & 756.50 & 3.76 & 755.68 & 5.99 & 0.82 & 7.08 & \multirow[t]{4}{*}{1.87} & \multirow[t]{4}{*}{3.55} \\
\hline FG5-107 & $\mathrm{AH}$ & 756.20 & 3.70 & 755.24 & 5.94 & 0.96 & 7.00 & & \\
\hline FG5-107 & $A J$ & 768.50 & 3.74 & 765.61 & 5.98 & 2.89 & 7.05 & & \\
\hline FG5-107 & AS & 756.30 & 4.08 & 753.43 & 6.04 & 2.87 & 7.29 & & \\
\hline FG5-105 & $\mathrm{AH}$ & 754.20 & 3.42 & 755.24 & 5.94 & -1.04 & 6.86 & \multirow[t]{4}{*}{-0.85} & \multirow[t]{4}{*}{3.55} \\
\hline FG5-105 & AJ & 765.90 & 3.44 & 765.61 & 5.98 & 0.29 & 6.90 & & \\
\hline FG5-105 & $A Q$ & 754.00 & 5.02 & 757.14 & 5.97 & -3.14 & 7.80 & & \\
\hline FG5-105 & AT & 754.10 & 3.48 & 754.09 & 6.01 & 0.01 & 6.94 & & \\
\hline FG5-236 & $A G$ & 754.60 & 3.98 & 755.68 & 5.99 & -1.08 & 7.20 & \multirow[t]{4}{*}{0.02} & \multirow[t]{4}{*}{3.62} \\
\hline FG5-236 & AJ & 765.70 & 4.02 & 765.61 & 5.98 & 0.09 & 7.20 & & \\
\hline FG5-236 & $A Q$ & 757.30 & 3.96 & 757.14 & 5.97 & 0.16 & 7.16 & & \\
\hline FG5-236 & AS & 754.40 & 4.28 & 753.43 & 6.04 & 0.97 & 7.40 & & \\
\hline FG5X-302 & $\mathrm{AH}$ & 756.40 & 3.62 & 755.24 & 5.94 & 1.16 & 6.96 & \multirow[t]{4}{*}{0.51} & \multirow[t]{4}{*}{3.50} \\
\hline FG5X-302 & $A Q$ & 759.10 & 3.62 & 757.14 & 5.97 & 1.96 & 6.98 & & \\
\hline FG5X-302 & AS & 753.00 & 3.64 & 753.43 & 6.04 & -0.43 & 7.05 & & \\
\hline FG5X-302 & AT & 753.40 & 3.62 & 754.09 & 6.01 & -0.69 & 7.01 & & \\
\hline
\end{tabular}


Table 10. Official DoE results for comparison SIM.M.G-K1 (according to Eq. 10). The uncertainty U UoE is the expanded uncertainty at $95 \%$ confidence of the weighted differences.

\begin{tabular}{|l|r|r|}
\hline \multicolumn{3}{|c|}{ Official Key Comparison Results } \\
\hline Gravimeter & DoE/ $\mu$ Gal & $U_{\text {DoE }} / \mu$ Gal \\
\hline FG5X-252 & 1.79 & 3.71 \\
\hline FG5X-216 & -0.40 & 3.82 \\
\hline FG5-204 & 2.14 & 3.54 \\
\hline FG5-105 & -0.85 & 3.55 \\
\hline
\end{tabular}

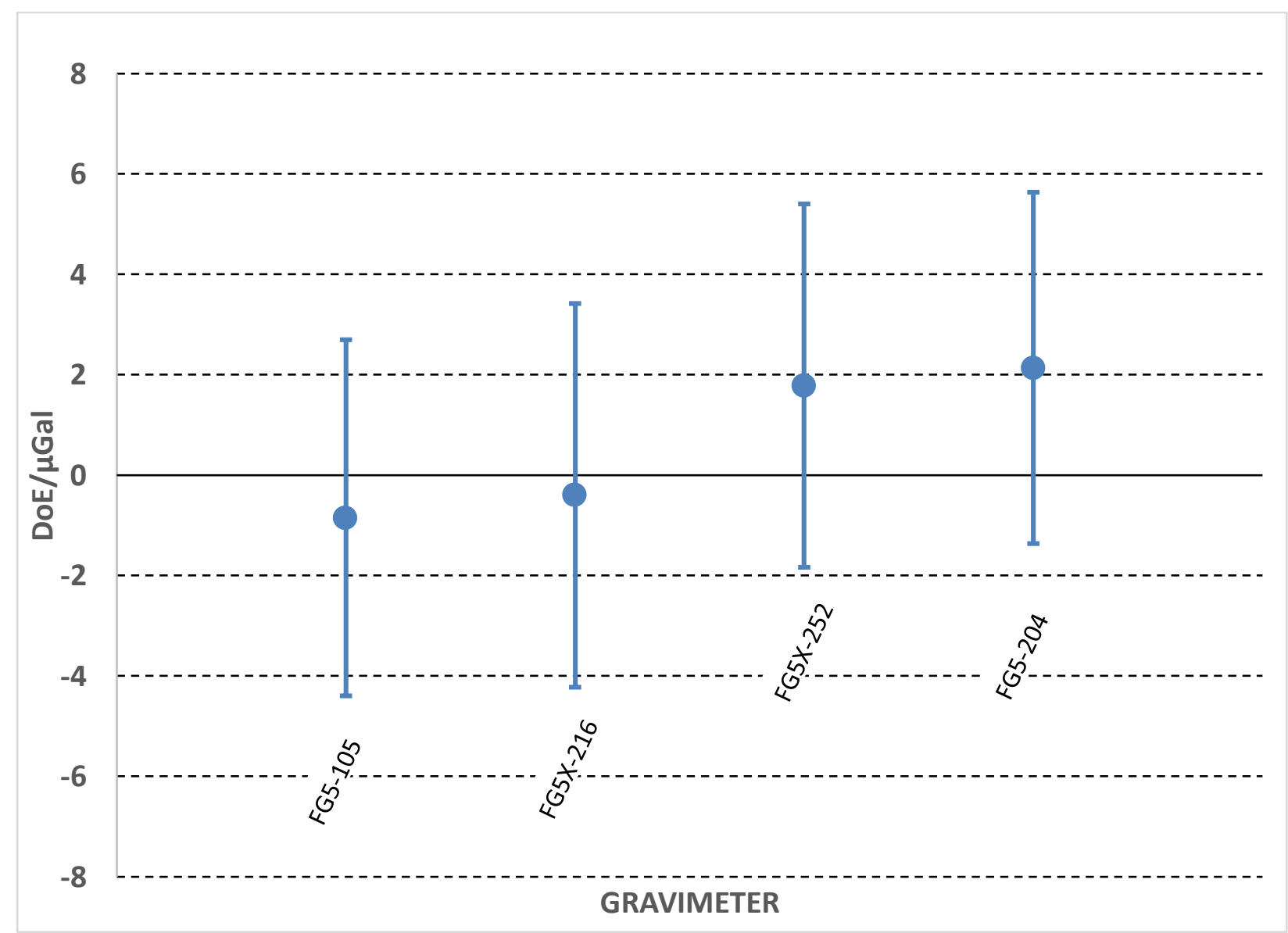

Figure 4. Official DoE results of the NMI/DI gravimeters participating in SIM.M.G-K1. The error bars represent the expanded uncertainties ( $\left.U_{D o E}\right)$ of the DoE at $95 \%$ confidence. 


\section{Conclusions}

Twelve absolute gravimeters were compared during the regional Key Comparison SIM.M.G-K1 of absolute gravimeters. Four gravimeters were from different NMIs and DIs. The comparison was linked to the CCM.G-K2 through EURAMET.M.G-K2 via the DI gravimeter FG5X-216. A subsequent verification of the link was provided by calculating the linking converter of SIM.M.G-K1 to CCM.G-K1 through the DoE of NMI gravimeter FG5-105 during CCM.G-K1. The two links differ by $0.36 \mu \mathrm{Gal}$, well within the uncertainties of the links, adding confidence in the stability of the two links separated by four years. Non-NMI/DI gravimeters participating did not contributed to the determination of the KCRVs. Their $g$-values were used to determine relative gravity ties for a better estimation of gravity differences between the 6 sites used during the comparison. One measurement from a non NMI/DIs was found to be inconsistent at the $95 \%$ confidence level and was excluded in the final estimate of the KCRVs. Overall, the results and uncertainties indicate an excellent agreement among the gravimeters, with a standard deviation of the gravimeters' DoEs better than $1.3 \mu \mathrm{Gal}$. 


\section{Appendix A: Pilot Study}

The Pilot Study results presented below are from a comparison where all participating gravimeters are treated as equivalent in terms of their contribution to the definition of the reference values (RVs). No link is considered to CCM.G.K2. The analysis follows the same procedure as in Section 6. The set of equations are given in Eqs. 4 and 5 with $d=0$ and the normalized weights calculated from Eq. 7. The normalized weights $\bar{w}_{i}$, the initial biases $\delta$, and pier Reference Values $g$ from the variance weighted LSA are given in Table A1.

Table A1. Normalized weights (wi), initial biases ( $\delta$ ), and pier Reference Values ( $g$ ) at a height of $125 \mathrm{~cm}$ for the Pilot Study using all the reported absolute measurements. The constant value $979622000.0 \mu \mathrm{Gal}$ is subtracted from the Reference Values. $U$ is the expanded standard uncertainty at $95 \%$ confidence $(k=2)$.

\begin{tabular}{|l|c|c|c|}
\hline Gravimeter & $\bar{w}_{i}$ & $\delta / \mu \mathrm{Gal}$ & $U / \mu \mathrm{Gal}$ \\
\hline FG5X-252 & 0.070 & 0.46 & 2.16 \\
\hline FG5X-216 & 0.059 & -1.74 & 2.35 \\
\hline FG5-238 & 0.091 & 0.99 & 1.88 \\
\hline FG5-234 & 0.076 & 0.48 & 2.04 \\
\hline FG5-218 & 0.086 & 3.00 & 1.92 \\
\hline FG5-301 & 0.062 & -0.12 & 2.29 \\
\hline FG5X-102 & 0.098 & -0.27 & 1.81 \\
\hline FG5-204 & 0.093 & 0.65 & 1.85 \\
\hline FG5-107 & 0.092 & 0.54 & 1.87 \\
\hline FG5-105 & 0.089 & -2.11 & 1.83 \\
\hline FG5-236 & 0.082 & -1.33 & 1.99 \\
\hline FG5X-302 & 0.102 & -0.93 & 1.77 \\
\hline
\end{tabular}

\begin{tabular}{|l|c|c|}
\hline Pier & $g / \mu \mathrm{Gal}$ & $U / \mu \mathrm{Gal}$ \\
\hline AG & 756.93 & 1.46 \\
\hline AH & 756.50 & 1.45 \\
\hline AJ & 767.00 & 1.48 \\
\hline AQ & 758.54 & 1.50 \\
\hline AS & 754.72 & 1.53 \\
\hline AT & 755.87 & 1.44 \\
\hline
\end{tabular}

The high level of consistency is the same as the initial results in section 7.1, with 31 degrees of freedom, chi square statistic $\chi^{2}=16.3$, probability $p(16.3 \mid 31)=0.99$ and Birge ratio of $R_{\mathrm{B}}=\sqrt{16.3 / 31}=0.73$. As before, following the consistency investigation of Section 7.2 , the input data of FG5-218 on pier AT has $R_{i j}=1.39$ and $E_{i j}=1.31$. This datum is omitted in the final analysis.

Following the procedure outlined in Section 7.4 and using Eq. 10, Table A2 and Figure A1 give the DoEs and their expanded standard uncertainties for the Pilot Study calculated from the differences between gravimeter measurements and the Reference Values in Table A1. All gravimeters are in equivalence. Note that the uncertainties $U_{j}$ of the Reference Values do not include an uncertainty from a linking converter. As with the Key Comparison SIM.M.G-K1, the overall results and uncertainties indicate good agreement among the gravimeters, with a standard deviation of the gravimeters' DoEs better than $1.3 \mu \mathrm{Gal}$ 
Table A2. DoEs from the Pilot Study (according to Eq. 10). The uncertainty $U_{D o E}$ is the expanded uncertainty at $95 \%$ confidence of the weighted differences.

\begin{tabular}{|l|r|r|}
\hline Gravimeter & DoE/ $\mu$ Gal & $U_{\text {DoE }} / \mu G a l$ \\
\hline FG5X-252 & 0.46 & 2.32 \\
\hline FG5X-216 & -1.72 & 2.49 \\
\hline FG5-238 & 1.14 & 2.06 \\
\hline FG5-234 & 0.61 & 2.21 \\
\hline FG5-218 & 2.16 & 2.40 \\
\hline FG5-301 & -0.02 & 2.45 \\
\hline FG5X-102 & -0.16 & 2.00 \\
\hline FG5-204 & 0.74 & 2.03 \\
\hline FG5-107 & 0.52 & 2.04 \\
\hline FG5-105 & -1.99 & 2.00 \\
\hline FG5-236 & -1.32 & 2.16 \\
\hline FG5X-302 & -0.81 & 1.96 \\
\hline
\end{tabular}

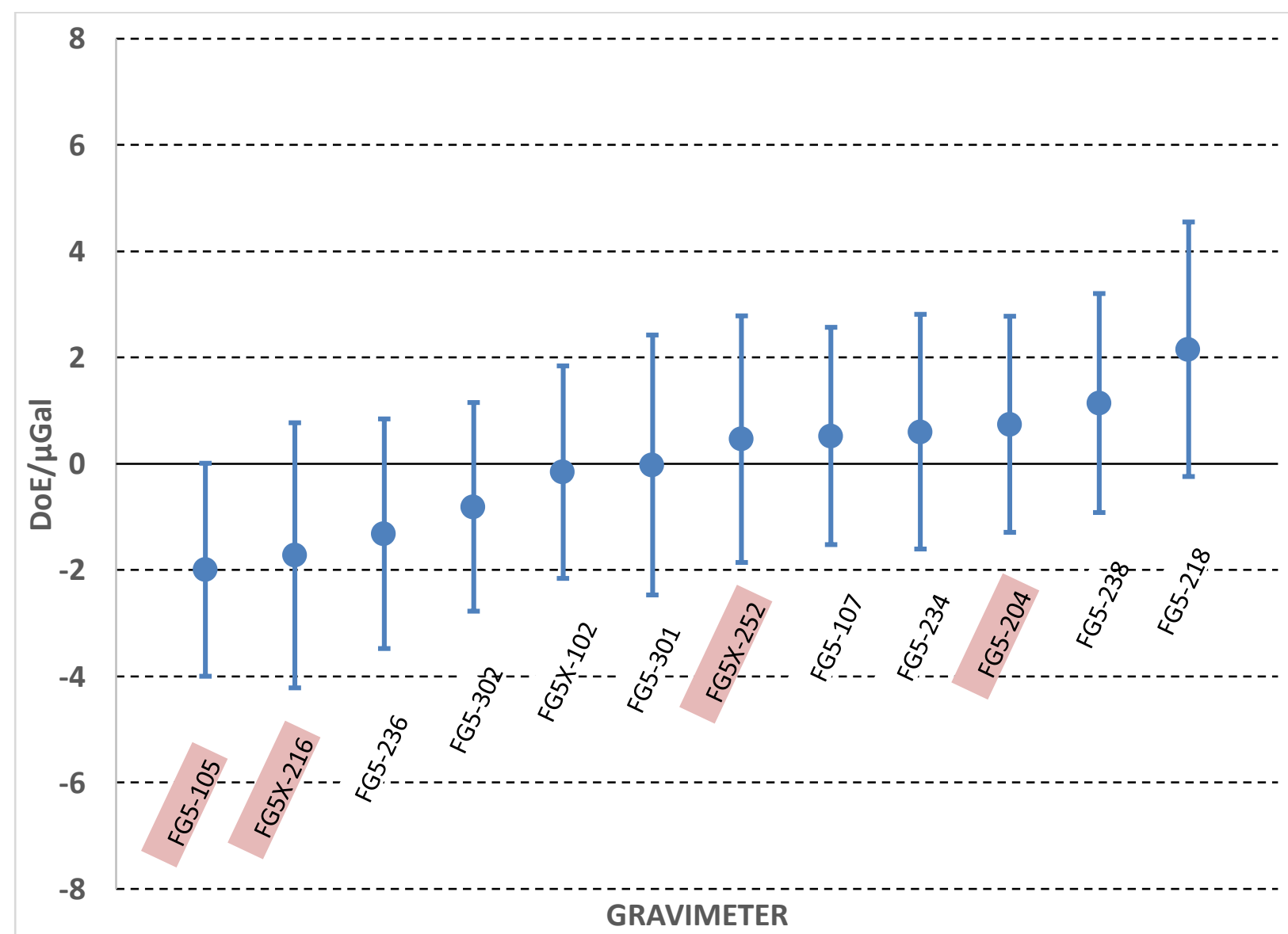

Figure A1. Degrees of Equivalence (DoE) from the Pilot Study calculated from the difference between the gravimeter measurements and the RVs. The error bars represent the expanded uncertainties (UDoE) of the DoE at 95\% confidence. Gravimeters of NMI/DIs are highlighted in pink. 


\section{References}

[1] Francis O, Baumann H, et al. (2015) CCM.G-K2 key comparison Metrologia 5207009 doi:10.1088/0026-1394/52/1A/07009.

[2] Pálinkáš V, Francis O, Val'ko M, Kostelecký J, Van Camp M, Castelein S, Bilker-Koivula M, Näränen J, Lothhammer ${ }^{\mathrm{A}}$, and Falk R (2017) Regional comparison of absolute gravimeters, EURAMET.M.G-K2 key comparison Metrologia 54 TS 07012.

[3] Niebauer T M (1989) The Effective Measurement Height of Free-fall Absolute Gravimeters Metrologia 26115 - 118.

[4] Timmen L (2003) Precise definition of the effective measurement height of free-fall absolute gravimeters Metrologia 40 62-65.

[5] Dam T M and Francis O (1998) 2 Years of Continuous Measurement of Tidal and Nontidal Variations of Gravity in Boulder, Colorado, Geophysical Research letters 25 (3) 393-396

[6] Smith D A, Saleh J, Eckl M. (2013) Optimizing an Absolute Gravimeter Comparison Schedule.http://www.ngs.noaa.gov/web/science_edu/presentations_library/files/agu_2013_p oster.pdf

[7] US Standard Atmosphere (1976), NASA-TM-X-74335, NOAA 77-16482.

[8] Petit G. and B Luzum, IERS Conventions (2010), IERS Technical Note 36, Frankfurt am Main: Verlag des Bundesamts fur Kartographie und Geodasie, 2010.

[9] Pálinkáš V, Jiang Z, Liard J (2012) On the effective position of the free-fall solution and the self-attraction effect of the FG5 gravimeters. Metrologia 49 552-559. ${ }^{9}$ Pálinkáš V, Jiang Z, Liard J (2012) On the effective position of the free-fall solution and the self-attraction effect of the FG5 gravimeters. Metrologia 49 552-559.

[10] Niebauer T, Billson R, Schiel A, van Westrum D, and Klopping F (2012), "The selfattraction correction for the FG5X absolute gravity meter" Metrologia, 50 1-8.

[11] van Westrum D and Niebauer T (2003) The diffraction correction for absolute gravimeters Metrologia $40258-263$.

[12] Koo A and Clare J F (2012) On the equivalence of generalized least-squares approaches to the evaluation of measurement comparisons Metrologia 49 340-348.

[13] Jiang Z, Pálinkáš V, Arias F E, Liard J, Merlet S, Wilmes H, Vitushkin L, et al. (2012) The 8th International Comparison of Absolute Gravimeters 2009: the first Key Comparison (CCM.G-K1) in the field of absolute gravimetry Metrologia 49666. 